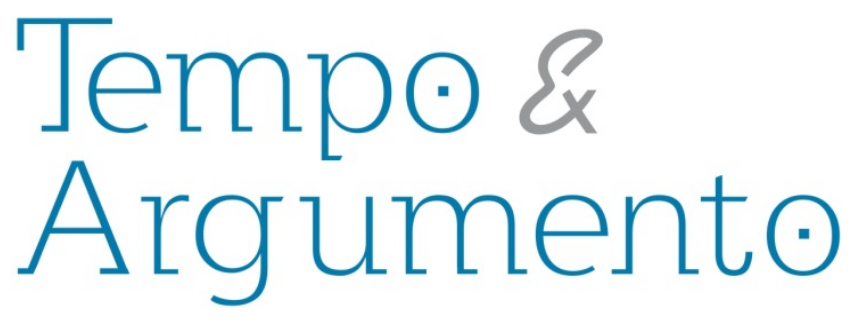

\title{
Sentidos de "digital" em disputa no currículo de história: que implicações para o ensino desta disciplina?
}

\begin{abstract}
Resumo
Este texto admite como base inicial de reflexão as muitas articulações que já se fizeram no campo educacional em torno dos significantes 'ensino' e 'tecnologia', em geral, fixando sentidos ligados à ideia de 'inovação', 'afinamento com os novos tempos' e/ou 'facilitador da aprendizagem'. No caso da disciplina História, fala-se recorrentemente que a utilização das chamadas tecnologias da informação e da comunicação (TICs) pode gerar novas práticas, indo de encontro ao tão combatido ensino 'tradicional', ligado à 'lógica da memorização'. Sem refutar ou corroborar tais afirmativas, e amparando-se nas contribuições das teorizações do discurso formuladas por Ernesto Laclau e Chantal Mouffe, a análise procura mostrar que fixar e disputar 'sentidos de digital' no currículo de História é uma ação política, que mobiliza/desloca a fronteira da própria definição do que é e do que não é a ciência/conhecimento histórico na contemporaneidade, provocando alterações, portanto, tanto na cultura histórica, quanto na cultura escolar. Tendo como empiria o Edital do Programa Nacional do Livro Didático (PNLD) 2015, entendido como texto curricular, o estudo evidencia e problematiza a forma como as disputas em torno da significação e fixação de 'sentidos de digital' têm aparecido na área de História, produzindo deslocamentos em meio às práticas articulatórias que fixam sentido para a interface 'ensino'-'tecnologia'.
\end{abstract}

Palavras-chave: História - estudo e ensino; Currículo.

\author{
Marcella Albaine Farias da Costa \\ Mestranda do Programa de Pós-Graduação \\ em Educação da Universidade Federal do \\ Rio de Janeiro - UFRJ. Graduada em História \\ pela Universidade Federal do \\ Rio de Janeiro - UFRJ. Cursando \\ especialização em Tecnologias da \\ Informação aplicadas à Educação na \\ Universidade Federal do \\ Rio de Janeiro - UFRJ. \\ Brasil \\ marcellaalbaine@gmail.com
}

\section{Carmen Teresa Gabriel Le Ravallec \\ Doutora em Educação pela Pontifícia Universidade Católica do Rio de Janeiro (PUC-RJ). Professora da Universidade Federal do Rio de Janeiro (UFRJ). Bolsista de Produtividade em Pesquisa do CNPq - Nível 2. Brasil carmenteresagabriel@gmail.com}

\footnotetext{
Para citar este artigo:

COSTA, Marcella Albaine Farias da; GABRIEL, Carmen Teresa. Sentidos de "digital" em disputa no currículo de história: que implicações para o ensino desta disciplina? Revista Tempo e Argumento, Florianópolis, v. 6, n. 12, p. 165 -185, mai./ago. 2014.
} 


\title{
"Digital meanings" in dispute at history currilum: what implications for teaching this discipline?
}

\begin{abstract}
This text comes from the comprehension that many articulations has been made in the educational field around the signifiers "teaching” and 'technology', in general, fixing meanings attached to idea of "innovation", "thinning with the new times" and/or "facilitator of learning". In the case of history discipline, there is repeatedly talk that the utilization of the so called information and communication technologies (ICTs) can generate new practices, going against the "traditional" teaching so opposed, connected to the 'logic of memorization'. Without refuting or corroborating such statements, and supported on contributions of discourse's theories formulated by Ernesto Laclau and Chantal Mouffe, the analysis seeks to show that fix and dispute "digital meanings" in history curriculum is a political action that mobilizes/displace the boundary of the very definition of what is and what is not science/ historical knowledge in contemporaneity, bringing changes, therefore, such in the historical culture, as in school culture. Having the Textbook National Program's Public Notice as empiria, understood as curricular text, the study highlights and discusses how the disputes about the meaning and fixation of 'digital meanings' have appeared in the history area, producing displacements among the articulatory practices that hold meaning for interface 'teaching' 'technology'.
\end{abstract}

Keywords: History - study and teaching. Curriculum. 
[...] digitalizar o passado é uma parte importante da história digital, mas isso não é o suficiente. Você ainda tem que aprender a apresentar essas informações de formas novas, atraentes, para pessoas que estão pensando de forma digital (SEDREZ, 2013). ${ }^{1}$

O trecho do debate acima referenciado apresenta uma das grandes questões que interpelam os historiadores e professores de História da atualidade, qual seja: a compreensão do que vem sendo chamado de história digital, em sua dimensão de ensino, pesquisa e divulgação.

Segundo Sedrez (2013), "para o pesquisador de história [a história digital] é uma coisa maravilhosa e um desafio em vários sentidos". O historiador e jornalista Bruno Leal de Carvalho, também participante do debate, informa que o termo história digital fora utilizado pela primeira vez no âmbito acadêmico em 1997, nos EUA, referindo-se à disponibilização de fontes primárias na web. Seu significado original foi sofrendo transformações, ampliando-se ao longo do tempo. Para ele, este "é um campo [ou, também, uma metodologia?] de estudos que busca representar, ensinar e produzir questões históricas a partir das chamadas mídias digitais, sobretudo a internet”.

Considerada uma "fonte nova, ainda pouco estudada, em rapidíssima expansão, totalmente inscrita no tempo presente e que deu ensejo a muito poucos exames críticos" (ROLLAND, 2004, p. 1), a internet gera, indubitavelmente, novas demandas no nosso "regime de historicidade" (HARTOG, 2013), marcando sua especificidade na articulação com o saber histórico, convidando-nos a (re)pensar nossas práticas a respeito do lugar de historiadores e/ou professores de História.

A expressão "história sem fio", utilizada por Lucchesi (2012), é bastante profícua para elucidar este novo cenário:

Dissemos 'sem fio', por um lado, por percebermos que a possibilidade dos deslocamentos humanos atuais - reais/analógicos e cibernéticos/virtuais simultaneamente - se dá graças às novas Tecnologias de Informação e Comunicação, que permitem uma nova noção de espacialidade, em que nem mesmo estar conectado a um

\footnotetext{
1 Trecho da fala de Lise Sedrez no Debate online - História Digital: Ensino, Pesquisa e Divulgação. Transmitido ao vivo pelo Café História em 26 nov. 2013.
} 
aparelho eletrônico fixo ligado a fios (wired) é necessário para circular no ciberespaço [...]. Por outro lado, chamamos a História desta contemporaneidade quase 'líquida' - como apreçaria Zygmunt Bauman de 'sem fio', pois, ao menos no que diz respeito à operação historiográfica a partir das fontes históricas próprias da Era Google, percebemos que os historiadores ainda não encontraram o fio da meada (LUCCHESI, 2012, p. 5-6).

De modo semelhante, uma breve aproximação com a bibliografia e os eventos ${ }^{2}$ especializados do campo da educação e da história, voltados ao ensino desta disciplina no ensino fundamental e médio, evidencia a presença dessa temática nos debates políticos e epistemológicos internos a essas áreas do conhecimento. É possível constatar que muitas articulações têm sido feitas no campo educacional em torno dos significantes 'ensino' e 'tecnologia', em geral, produzindo e fixando sentidos ligados à ideia de 'inovação', 'afinamento com os novos tempos' e/ou ‘facilitador da aprendizagem'.

Estudos recentes da área do ensino de história (GABRIEL, 2012, ARRUDA, 2011) referem-se à presença de uma forte associação discursiva, nos textos curriculares dessa área, entre inovação e as chamadas tecnologias da informação e da comunicação (TICs) no combate a um ensino qualificado pejorativamente de tradicional.

As citações que se seguem, embora com perspectivas diferenciadas, reforçam esta afirmação. O processo de homogeneização de um ensino de história inovador contra um inimigo comum - a história tradicional -, denunciado no texto de Gabriel (2012), é confirmado por Arruda (2011), que aposta, de forma explícita, no potencial das novas TICS na produção de novas práticas em superar os entraves de um modelo tradicional de aprendizagem baseado em uma perspectiva linear, justamente um dos principais traços desse tão combatido ensino 'tradicional'. Enquanto para Gabriel:

Uma leitura dos textos curriculares - propostas, livros didáticos, programas de ensino - produzidos nesses últimos quarenta anos, bem como dos textos acadêmicos permite apontar que a 'grande inimiga' a ser combatida desde os anos 80 na historiografia escolar é a matriz disciplinar sobre a qual se apoiaria o ensino de História, identificada pelo adjetivo 'tradicional', de conotação negativa, associada à perspectiva

\footnotetext{
${ }^{2}$ Entre estes, podemos citar os encontros da Associação Nacional de História (Anpuh), o Encontro Nacional Perspectivas do Ensino de História e o Encontro Nacional dos Pesquisadores do Ensino de História (Enpeh).
} 
positivista e contra a qual se articularam, e ainda se articulam, as demandas de inovação do ensino dessa disciplina (GABRIEL, 2012, p. 197).

Para Arruda (2011), o caminho da inovação, em particular por meio das novas TICs, é promissor:

Ao contrário do modelo tradicional de aprendizagem - baseado em uma perspectiva linear -, no qual os bens culturais ficam encerrados em espaços físicos fechados a qualquer público, na perspectiva da aprendizagem mediada por tecnologias digitais, o conhecimento está vinculado aos sujeitos de diversas formas e meios, por meio de sua disponibilização em espaços públicos digitais, ainda que estes espaços estejam em processo de ampliação do seu acesso (ARRUDA, 2011, p. 4).

A partir destas breves colocações, e entendendo que não existem respostas prontas para os novos desafios cotidianamente colocados ao nosso ofício de professor e pesquisador, interessa-nos, neste texto, compreender como a incorporação das novas tecnologias, tanto na cultura histórica (RUSEN, 2009), como na cultura escolar (FORQUIN, 1992), produz efeitos na configuração do conhecimento histórico, legitimado para ser ensinado na educação básica.

Este recorte se justifica na medida em que entendemos que a produção e distribuição de tal conhecimento pressupõe a mobilização e articulação de elementos específicos tanto do campo da História como o da Educação. Afinal, para Rusen:

A cultura histórica se refere portanto a uma maneira particular de abordar interpretativamente o tempo, precisamente aquela que resulta em algo como história enquanto conteúdo da experiência, produto de interpretação, medida de orientação e determinação da finalidade (RUSEN, 2009: tradução livre).

A categoria cultura escolar, na perspectiva trabalhada por Forquin (1992), nos remete, por sua vez, diretamente às coisas de escola, possibilitando definir o escolar de forma a considerar as especificidades desse tempo-espaço colocando em evidência a importância da relação com o conhecimento nesse contexto discursivo.

Desse modo, vimos buscando, no âmbito do Grupo de Estudos Currículo, Cultura e Ensino de História (Gecceh), do Núcleo de Estudos do Currículo (NEC) da UFRJ, dialogar 
Defendemos que esta forma de entrar no debate permite criar pontos de interseção capazes de produzir um sistema discursivo conhecido como cultura histórica escolar, potencializando o entendimento de história-ensinada em que temos apostado no âmbito do nosso grupo de pesquisa, traduzido de forma sintética na citação abaixo, que reforça a importância de operar de forma articulada a cultura histórica e a cultura escolar:

Com efeito, e aparentemente de forma paradoxal, defendo que a construção de argumentos mais consistentes do ponto de vista teórico, para a defesa das particularidades, passa pela assunção do comum, daquilo que carrega uma dimensão do universal. Como entender a especificidade do "escolar" que adjetiva o conhecimento histórico, sem compreender a complexidade do substantivo "história" percebido como conhecimento científico? (GABRIEL, 2012, p. 188).

Entre esses autores, eleitos como interlocutores privilegiados, há quem contribua para a produção da crítica às perspectivas essencialistas na leitura do social, em particular os que operam com as abordagens discursivas na pauta do pós-fundacional (LACLAU \& MOUFFE, 2005, MARCHART, 2009), ajudando a pensar a dimensão políticaepistemológica no campo do currículo e do ensino do ensino de história.

Entendemos que esse tipo de abordagem permite assumir, no caso do presente trabalho, os desafios colocados pelas novas tecnologias para a produção epistemológica do conhecimento histórico como objeto de ensino e, simultaneamente, nos distanciar de visões que ora as consideram panaceia para todas as mazelas da educação, ora fonte de todos os males.

Interessa-nos, assim, compreender os mecanismos discursivos mobilizados no processo de hegemonização/homogeneização/universalização do sentido de "um ensino de história inovador". Estudos preliminares dessa temática, realizados no Gecceh, têm apontado que alguns termos/significantes foram mobilizados com recorrência nesses debates, assumindo a função discursiva de articular diferentes demandas de conhecimento. Entre esses significantes, destaca-se o termo digital, expressão de ponto 
nodal nessas lutas pela significação. Afinal, não é por acaso que este termo é utilizado para qualificar outras formas de acesso ao passado, tanto no âmbito acadêmico como no escolar. Como aponta Arruda (2011, p. 10), “o ensino de História pode ser potencializado significativamente, por permitir, por meio da informática, a materialização, ainda que virtual, do passado".

Desse modo, procuramos, aqui, evidenciar os 'sentidos de digital' disputados no fazer história em diferentes esferas de problematização desse conhecimento, entendendo esses fazeres como ação política que mobiliza/desloca a fronteira da própria definição do que é e do que não é a ciência histórica e ensino de história na contemporaneidade.

Como empiria, selecionamos o Edital do Programa Nacional do Livro Didático (PNLD) 2015, entendido como texto curricular, que, em sua formulação, articula essas diferentes esferas ou contextos de produção do conhecimento histórico, bem como procura regular algumas fixações discursivas para a interface 'ensino de historia' 'tecnologia digital'.

Optamos por organizar o presente trabalho em duas seções. Na primeira, explicamos o referencial teórico aqui privilegiado, explicitando a nossa leitura do diálogo estabelecido entre currículo (de história) e novas tecnologias, procurando explorar seus efeitos na relação estabelecida com o passado, tanto no âmbito da pesquisa histórica, quanto na escola da educação básica. $\mathrm{Na}$ segunda seção, apresentamos a análise do edital mencionado anteriormente, no campo do currículo de história, procurando sublinhar os mecanismos discursivos mobilizados para a fixação do sentido de digital em meio às lutas pela significação de sentido hegemônico de ensino de História inovador.

\section{Currículo de história e tecnologia digital: possíveis articulações discursivas}

[...] a teoria [social] do discurso tem o potencial de ser uma ferramenta de compreensão do social, uma vez que seu próprio entendimento se dá, nesta perspectiva, a partir da construção de ordens discursivas, sendo a questão do poder central e constituidora de relações sociais. [...] Laclau articula uma série de noções e de conceitos oriundos de várias áreas do conhecimento, como o marxismo, a filosofia desconstrutivista de Derrida, a psicanálise, sobretudo lacaniana, a linguística, o 
estruturalismo, o pós-estruturalismo. A partir de noções advindas dessas áreas, o autor constrói um aparato teórico original, inserido numa matriz contemporânea, pós-estruturalista, que contempla a contingência, a precariedade, a indeterminação e o paradoxo como dimensões ontológicas do social (MENDONÇA, 2009, p. 153-154).

Não cabe nos limites deste texto, tendo em vista o recorte aqui privilegiado e a densidade teórica da abordagem explicitada na citação acima, um mergulho aprofundado nesse quadro teórico. Preferimos, nesta seção, destacar algumas ferramentas conceituais elaboradas no âmbito da Teoria do Discurso de Ernest Laclau e Chantal Mouffe, que entendemos serem potentes para a análise que aqui nos propomos realizar.

Uma primeira ferramenta consiste no próprio termo discurso, diretamente relacionado ao entendimento de crítica formulada por esses teóricos às leituras essencialistas de mundo. Importa sublinhar a radicalidade dessa crítica, que extrapola a ideia de historicidade e traz para o debate o desafio da definição.

Este desafio nos situa frente à complexa relação entre pensamento e realidade que precede e orienta as escolhas em termos de filiações disciplinares ou de interlocuções teóricas nos diferentes campos de conhecimento com os quais dialogamos. Nessa perspectiva, emerge a contribuição das abordagens discursivas para a construção teórica da crítica às perspectivas essencialistas a respeito da compreensão dos processos constitutivos do social.

Com trajetórias em campos de conhecimento distintos e com recortes também diferenciados, essas abordagens compartilham o reconhecimento da centralidade da categoria discurso na luta pela definição do social. A potência do termo discurso, que nos interessa trabalhar, está justamente no fato de ele propor uma forma de enfrentamento das complexas relações entre pensamento e realidade, sujeito e objeto, simbólico e material. Nessas abordagens, discurso não é termo percebido para designar uma operação mental, ideal, em oposição a ação ou realidade. Ele é relacional e da ordem do material: uma categoria que investe na crítica à ideia de essência, que assume radicalmente as implicações políticas e epistemológicas de nossa condição de ser na e da linguagem e que é dessa e nessa condição que pensamos, significamos e agimos no mundo.

Afinal, como questiona Gabriel: 
Como significar "realidade" em plena crise representacional que coloca em xeque explicações que mobilizam sentidos de linguagem, aqui percebida como reflexo ou espelho do mundo? O que entender por historicidade quando algumas garantias acerca dos sentidos atribuídos à nossa orientação temporal são gravemente abaladas em nosso presente? Quando uma história tautológica que nos oferecia uma direção pré-determinada do futuro já vem sendo, há muito tempo combatida? Quando uma percepção do passado como "algo que realmente aconteceu vem sendo problematizado"? (GABRIEL, 2013).

A compreensão desse argumento é importante para evitar alguns equívocos. Não se trata de buscar um sentido último, mais verdadeiro ou oculto, das palavras articuladas em um texto quando analisamos algum discurso. O desafio é justamente ficar no nível das palavras, reconhecendo, ao mesmo tempo, que ao fazê-lo não nos detemos apenas nas palavras. Como afirma Burity (2008), se não há ação social sem significação, toda significação está inserida - ainda que de forma instável e provisória - em um discurso, isto é, na materialidade do dito.

Situamos, assim, o presente texto no panorama das teorizações discursivas em uma perspectiva pós-fundacional:

Em diálogo com Olivier Marchart (2009), entendo por essa expressão "uma constante interrogação das figuras metafísicas fundacionais, tais como a totalidade, a universalidade, a essência e o fundamento" (MARCHART, 2009, p. 14, tradução livre). [...] a perspectiva de ver e ler o mundo pós-fundacional aqui defendida, [...] não se confunde com um anti-fundacionismo, por meio do qual caberia um "tudo vale". O que está sendo problematizado não é a possibilidade de operar com fundamentos mas sim o seu estatuto ontológico (GABRIEL, 2013, p. 292).

Assim como o pós-estruturalismo não nega a estrutura, o pós-fundacionismo não nega o fundamento; o uso deste prefixo, porém, estabelece um deslocamento. O pós-estruturalismo estabelece, sim, o fim das estruturas centradas, pré-fixadas; “contrapondo-se ao estruturalismo, o pós-estruturalismo critica o fato de ele não perceber que a própria ideia de estrutura estaria ela mesma marcada pela linguagem" (LOPES \& MACEDO, 2011, p. 39).

Definir, nomear é, pois, um ato político em meio às lutas de significação em um sistema de diferenças no qual não existem sentidos preestabelecidos. Nessa perspectiva pós-fundacional, discurso, por significar uma categoria que une palavras e ações, não é, pois: 
[...] algo limitado aos domínios da fala e da escrita, mas um conjunto de elementos nos quais as relações desempenham um papel constitutivo. Isso significa que estes elementos não preexistem ao complexo relacional, mas se constituem por meio dele (LACLAU; MOUFFE, 2005, p. 86, tradução livre.)

Outra ferramenta importante, diretamente relacionada à questão da definição, diz respeito à noção de prática articulatória, responsável pelo entendimento dos mecanismos discursivos mobilizados no jogo político da definição. Não é por acaso que, para Laclau (2011, p. 143), discurso é "uma totalidade estruturada resultante da prática articulatória".

$\mathrm{Na}$ medida em que o fechamento simbólico do "social" não pode se justificar por nenhuma essência, isto é, por qualquer fundamento 'fora' do jogo da linguagem, o conceito de "articulação" assume um papel central na construção do argumento nesse quadro teórico. Nesse movimento de significação/definição, articular implica simultaneamente criar equivalências entre as diferenças e produzir uma ruptura, um corte radical, antagônico, que impede o fluxo contínuo e infinito de equivalências entre sentidos. Todo sistema de diferenças seria, portanto, caracterizado por uma ambivalência instituída pela fronteira, que delimita aquilo que "é" a partir daquilo que "não é".

A lógica da diferença atuaria no estancamento, na quebra de cadeias de equivalência existentes por meio da produção de diferenças radicais, isto é, de limites que funcionam como um “bloqueio da expansão contínua do processo de significação" (LACLAU, 2011, p. 71). A compreensão dessas duas lógicas em meio às lutas de significação é importante para o entendimento do papel atribuído ao político nesse quadro teórico.

Assim, “qualquer hegemonia é sempre instável e penetrada por uma ambiguidade constitutiva" (LACLAU, 2011, p. 78) e se instaura no movimento de produção de cadeias de equivalência que visam a domesticar discursivamente a incompletude do social. Hegemonizar significa investir no preenchimento do sentido de "universal" que, por sua vez, se oferece como representação impossível. Como explicita Laclau (2005, p. 95), "a operação pela qual uma particularidade assume uma significação universal incomensurável consigo mesma é o que denominamos hegemonia".

Desta forma, interessa-nos explorar as lógicas da equivalência e da diferença mobilizadas nos processos de fixação do sentido hegemônico de digital nos debates contemporâneos. Ao invés de operar com a ideia de que há algum sentido previamente dado e naturalizado para esse 
Optamos aqui pensar essas articulações como contexto discursivo privilegiado e, como já explicitado anteriormente, o Edital do Programa Nacional do Livro Didático (PNLD) 2015, considerado como texto curricular. Este recorte nos remete aos debates do campo do currículo. Coerentes com o quadro teórico escolhido, reconhecemos as distintas possibilidades, as disputas e os embates na definição sobre o que é e o que não é currículo, assumindo, assim, que, na impossibilidade de "apontar para algo que Ihe seja intrinsecamente característico", nos resta apenas explicitar nossos "acordos sobre os sentidos de tal termo, sempre parciais e localizados historicamente" (LOPES; MACEDO, 2011, p. 19). Assim, significamos currículo como "espaçotempo de fronteira", na perspectiva defendida por Macedo (2006) e traduzida no trecho abaixo:

Não falo, portanto, de um espaço-tempo cultural qualquer, embora também dele, mas do currículo escolar (no Brasil de hoje). Quero, ainda, antes de ler esse currículo, deixar clara minha recusa em aceitar distinções entre o currículo formal e o vivido [...] a produção dos currículos formais e a vivência do currículo são processos cotidianos de produção cultural, que envolvem relações de poder tanto em nível macro quanto micro. Em ambos são negociadas diferenças. De ambos participam sujeitos culturais com seus múltiplos pertencimentos (MACEDO, 2006, p. 288).

Ou ainda, e em diálogo com as teorizações do discurso, operamos com a compreensão de currículo como "lugar de enunciação" (MACEDO, 2006), ou seja, como "um lugar chave onde se estabelecem relações entre a língua e o mundo, isto é, onde são produzidos, disputados, negociados, discursivamente, sentidos sobre o mundo" (GABRIEL; LEITE e VENERA, 2012).

Entre outras possíveis definições de currículo, a ideia de um web currículo nos parece igualmente potente. Por ora, tendo em vista o recorte de nosso trabalho, interessa-nos menos operar com essa expressão como campo empírico do que reconhecer a potencialidade dessa designação em meio aos debates curriculares em geral, e do ensino de história em particular. Diante dos desafios a que o digital expõe historiadores e professores de História do século XXI e buscando estabelecer práticas articulatórias possíveis em torno dos significantes 'ensino', 'pesquisa' e 'tecnologia', 
coloca-se o desafio da construção do que pode ser designado por web currículo de história.

A ideia de web currículo tem sido trabalhada por Almeida (2010), Almeida \& Silva (2011) e Almeida \& Valente (2012) no âmbito da Linha Novas Tecnologias na Educação do Programa de Pós-Graduação em Educação: Currículo da Pontifícia Universidade Católica de São Paulo (PUC-SP). Segundo essas autoras, este:

É o currículo que se desenvolve por meio das tecnologias digitais de informação e comunicação, especialmente mediado pela internet. Uma forma de trabalhá-lo é informatizar o ensino ao colocar o material didático na rede. Mas o web currículo vai além disso: ele implica a incorporação das principais características desse meio digital no desenvolvimento do currículo. Isto é, implica apropriar-se dessas tecnologias em prol da interação, do trabalho colaborativo e do protagonismo entre todas as pessoas para o desenvolvimento do currículo. É uma integração entre o que está no documento prescrito e previsto com uma intencionalidade de propiciar o aprendizado de conhecimentos científicos com base naquilo que o estudante já traz de sua experiência. O web currículo está a favor do projeto pedagógico. Não se trata mais do uso eventual da tecnologia, mas de uma forma integrada com as atividades em sala de aula ${ }^{3}$.

Almeida \& Silva (2011, p. 8) afirmam que "não se trata de ter as tecnologias como um apêndice ou algo tangencial ao currículo e sim de buscar a integração transversal das competências no domínio das TDIC [tecnologias digitais de informação e comunicação] com o currículo, pois este é o orientador das ações de uso das tecnologias".

Para nós, ao pensar na formulação de um web currículo de história, dialogando com e contra algumas das proposições fixadas do termo e considerando os fluxos de cientificidade que advêm deste campo disciplinar para pensar a dimensão do ensino e da pesquisa histórica, algumas questões centrais se colocam e podem ser assim formuladas:

- Visitar o passado na era digital significa mudar a natureza desse conhecimento histórico ou apenas ampliar as formas de lhe ter acesso? Ou ainda:

- Compreendendo a temporalidade como elemento constitutivo do conhecimento histórico (COSTA; GABRIEL, p. 133) e que a reflexão do/com o tempo "desempenha a função discursiva de corte antagônico entre o que é e o que não

\footnotetext{
${ }^{3}$ (http://revistaescola.abril.com.br/planejamento-e-avaliacao/avaliacao/entrevista-pesquisadora-puc-sptecnologia-sala-aula-568012.shtml). Acesso em: 7 mar. 2014.
} 
é uma perspectiva histórica na análise do social” (GABRIEL; MORAES, 2013, p. 33), que nova tessitura passa a ser oferecida pelas novas mídias na articulação entre passado, presente e futuro, abrindo-nos outras possibilidades de operar com as categorias de simultaneidade, ruptura, permanência, etc.?

Concordamos com Ferreira \& Marques (2012, p. 233) quando nos dizem que "muitas vezes as novas tecnologias são utilizadas apenas como recursos e quase nunca problematizadas como fenômeno que modifica as próprias noções de tempo e espaço dos alunos [e também de professores e pesquisadores]". Faz-se necessário pensar em que medida as estruturas espaciais e temporais são modificadas, considerando os projetos de futuro que hoje vigoram em uma sociedade como a nossa, com suas demandas de igualdade, diferença e conhecimento.

Ao falar em conhecimento, se partirmos da compreensão de que essas novas tecnologias permitem potencializar a democratização do conhecimento histórico, que saberes em circulação no ciberespaço buscaremos legitimar? Afinal, como nos lembra Rolland (2004, p. 2), vivemos uma época em que "o escrito 'virtual', raramente assinado, oferece, amiúde, aos consumidores, sem que o internauta o saiba, uma história sem historiador". Além disso:

A Internet configura-se como uma nova categoria de fontes documentais para pesquisas históricas. Em especial os pesquisadores do Tempo Presente, após o advento da Internet, passaram a contar com um aporte quase inesgotável de novas fontes. Contudo, já na segunda década do século XXI, ainda são poucas as pesquisas históricas que utilizam a Internet como fonte primária (ALMEIDA, 2011, p. 9).

A extensão da problemática abarca, então, questões relativas à produção do conhecimento histórico e à sua recontextualização didática, envolvendo, portanto, os que estão no meio acadêmico e os que militam no espaço escolar. É importante nos posicionar - sabendo que este é um posicionamento em meio ao jogo político - a respeito do que queremos atribuir como pesquisa/ensino inovadores, fixando, ainda que provisória e precariamente, os sentidos de digital no qual temos interesse em investir e ao qual pretendemos hegemonizar.

É a esta produção de 'sentidos de digital' - tendo como empiria o mais recente Edital do Programa Nacional do Livro Didático (PNLD) 2015 - que dedicaremos nossos esforços de análise na próxima seção, visto que tanto a dimensão do ensino quanto a da pesquisa na referida área estão perceptivelmente afetadas e com desafios importantes a enfrentar neste começo de século. 


\section{Fixando sentidos de 'digital' e 'não-digital' nos textos curriculares de história: problemáticas e apostas}

A escolha de um texto curricular (o Edital) produzido no âmbito da mais recente edição do Programa Nacional do Livro Didático (PNLD) voltado ao ensino médio, justifica-se em dois níveis de argumento. Um primeiro refere-se ao lugar atribuído ao livro didático nos debates curriculares. O segundo pela intencionalidade específica expressa nesse edital em incluir, pela primeira vez em nível de ensino médio, nessa política de avaliação, os livros didáticos digitais.

Objeto de grande complexidade (MONTEIRO, 2009), o livro didático pode ser visto como instrumento pedagógico, referência a conteúdos selecionados, objeto cultural, documento histórico e mercadoria. A introdução recente dessa outra modalidade o coloca no centro dos debates sobre a articulação entre ensino, currículo, conhecimento e tecnologia. Estudos recentes, como os de Costa e Ralejo (2013), buscam investigar como estão se estabelecendo possíveis diálogos entre diferentes (mas não opostos) universos que envolvem a 'tradição' e a 'inovação' entre os livros didáticos - parte integrante do currículo escolar - e as demandas tecnológicas. Estariam os primeiros perdendo espaço diante de um público escolar, em grande medida de "nativos digitais" (PRENSKY, 2001)? Ou autores, editoras e políticas públicas oficiais estariam se mobilizando para realizar uma "transposição didática das inovações tecnológicas" (SCHMIDT, 2009) comuns no tempo presente, como forma de dialogar e criar mecanismos de aceitabilidade com este seu público-alvo?

Importa sublinhar que a versão do Guia do Programa Nacional do Livro Didático de Ensino Médio de História (PNLD) 2012 - documento das políticas públicas de avaliação das coleções de obras didáticas ${ }^{4}$, entendido por nós como um texto curricular - apresentou pela primeira vez, como um de seus critérios avaliativos, justamente os usos pedagógicos da internet no ensino de História, traduzindo os efeitos de um movimento maior de apropriação da internet por jovens. Uma forma, a nosso ver, de a escola fazer a gestão dessas demandas tecnológicas que tendem a se articular a uma visão de modernização da instituição escolar.

O recente Edital PNLD 2015 (objeto de análise deste trabalho), que "tem por objeto a convocação de editores para o processo de inscrição e avaliação de obras didáticas destinadas aos alunos e professores do ensino médio das escolas públicas federais e das que integram as

\footnotetext{
${ }^{4}$ Criado em 1985.
} 
redes de ensino estaduais, municipais e do Distrito Federal" (BRASIL, 2013, p. 1), traz a essa discussão algo de novo em relação à edição anterior. Enquanto no Guia PNLD 2012, a avaliação levava em consideração exclusivamente a indicação de sites $^{5}$, o texto do Edital de 2015 trabalha com a ideia de objetos educacionais digitais (OEDs).

Entendendo esta publicação como um texto curricular e em diálogo com o referido quadro teórico e com as colocações feitas anteriormente, a intenção desta seção é perguntar de que forma têm aparecido na área de História as disputas em torno da significação e fixação de 'sentidos de digital'.

O Edital PNLD 2015 classifica as obras em Tipo 1 (obras multimídias, compostas de livros digitais e livros impressos) e Tipo 2 (livros impressos e livros em PDF), uma vez que, de acordo com o item 4.2.2, "os livros digitais deverão apresentar o conteúdo dos livros impressos correspondentes, integrados a objetos educacionais digitais [OEDs]" (BRASIL, 2013, p. 3).

É interessante, neste texto curricular, analisar a mobilização das lógicas de equivalência e de diferença acionadas no jogo da definição do significante digital e analisar as diferentes unidades diferenciais articuladas em uma cadeia de equivalência com o intuito de atribuir sentidos a estes objetos digitais. No item 4.2.3, é possível perceber os diferentes elementos que configuram sua natureza classificatória:

entende-se por objetos educacionais vídeos, imagens, áudios, textos, gráficos, tabelas, tutoriais, aplicações, mapas, jogos educacionais, animações, infográficos, páginas web e outros elementos" (BRASIL, 2013, p. 3, grifo nosso).

Nesse movimento articulatório, chama atenção a expressão "e outros elementos", que simultaneamente fecha e deixa aberta essa cadeia equivalencial. Entendemos a mobilização dessa expressão como uma estratégia política que se apresenta como faca de dois gumes: de um lado, a abertura traduz maior flexibilidade na fronteira entre o que é e o que não é digital, permitindo uma expansão dessa cadeia definidora e a possibilidade de incorporar outras demandas. De outro, ela enfraquece o potencial subversivo desse termo na medida em que não representa uma sutura, ainda que provisória, suficientemente potente para bloquear os fluxos de significação.

\footnotetext{
${ }^{5}$ Foram avaliados os seguintes critérios: acessibilidade; tipos de linguagem; interatividade; objetivos didático-pedagógico do uso dos sites; referências de imagens e fontes neles utilizadas; orientação para o professor visando à sua exploração, integração dos sites com os conteúdos, sua utilização em diferentes situações de ensino-aprendizagem; informações complementares e orientações que auxiliem os alunos a explorar o conteúdo, os recursos disponíveis e a oferta de recursos variados quanto às possibilidades de significação história.
} 
Afinal, pelo quadro teórico interpretativo que adotamos, entendemos que só podemos marcar nosso posicionamento sobre o que algo é quando mobilizamos a lógica da diferença, sendo esta a responsável por estancar as cadeias de equivalência, produzindo diferenças, antagonismos que funcionam como limites radicais entre aquilo que é daquilo que não é (FERREIRA; GABRIEL, 2012).

A nosso ver, essa ausência de fechamento, de corte antagônico, permite que seja significado como "objetos digitais" significantes como, por exemplo, textos ou imagens estáticos que, ao invés de contribuírem para incorporar as demandas tecnológicas e deslocar eventualmente as fronteiras hegemônicas do conhecimento histórico escolar, reforçam uma prática que Cysneiros (1999) classifica como "inovação conservadora”: o reforço de antigos hábitos, através de recursos "modernos", sem a exploração dos potenciais exclusivos daquele determinado recurso.

Os vestígios discursivos aqui assinalados são, em nosso entender, uma porta de entrada instigante para debater que fluxos de sentidos o significante 'digital' abre como campo de possibilidades 'inovadoras' ao ensino desta disciplina.

Uma leitura mais atenta deste texto aponta, contudo, para a presença, ainda que pontual, de um significante que, por ora, talvez na falta de um mais potente, exerça a função do que Laclau chama de "exterior constitutivo" de uma cadeia de equivalência. Dito de outra maneira, aquele que é jogado, é expelido para fora como um Outro, que simultaneamente impede e possibilita que o processo de significação se realize. Com efeito, o termo ‘digitalizado’ aparece no item 7.2.5, explicitando essa função discursiva ao afirmar que "não será aceito livro impresso digitalizado como livro digital".

Na disputa em busca de definições sobre o que é, ou melhor, sobre aquilo que queremos que se entenda por 'digital' - algo que se dá por meio do jogo da linguagem -, a expressão 'digitalizado' acaba por formar seu exterior constitutivo, algo não-digital, mas, justamente por negar seu sentido, passa a constituir condição de existência de algo que lhe é diferencial.

Importa questionar, no entanto, se a diferença entre 'digital' e 'digitalizado' é suficientemente potente para deslocar a fronteira do que, por exemplo, é ou não é passado, ensino de historia ou historiografia, ou se ela se limita a reproduzir e a realimentar a cadeia hegemônica definidora de tecnologia como mera ferramenta ou suporte. Esta suspeita é reforçada quando constatamos igualmente que o edital não traz maiores especificações sobre interatividade, não faz exigências diretas e explícitas sobre a necessidade de manifestação, nestes objetos digitais, de possibilidades concretas de os usuários (alunos e professores) "irem e virem" 
(ideia da hipertextualidade), visando à autoria e à liberdade dos caminhos a trilhar para construir o conhecimento - uma das maiores potências do digital.

Há um avanço, mas este avanço ainda é - e talvez o seja por muito tempo, justamente pela "novidade" e por possíveis desconfortos que o digital gera na cultura escolar e na cultura histórica - acompanhado de muitos perigos e limitações. Lembremos Almeida \& Grinberg quando alertam que:

O ensino de história vem passando por uma grande renovação nos últimos anos, principalmente no que se refere à incorporação de novos temas e novas abordagens - dos quais a história da África e do cotidiano são bons exemplos [...]. Essa renovação, no entanto, ainda não encontrou grande correspondência na metodologia de ensino da disciplina (ALMEIDA; GRINBERG, 2009, p. 201).

Como interesse para estudos futuros, é possível analisar se ou em que medida esses OEDs fornecem orientações aos docentes para efeito de exploração junto aos discentes (inclusive no aspecto das estratégias e dos recursos didáticos a serem empregados); se estes objetos apresentam, de maneira articulada com os conteúdos, recursos variados quanto às possibilidades de significação histórica (diferentes tipos de textos, imagens, fontes históricas); se corrigem e atualizam conceitos e informações históricas, incorporando a renovação historiográfica no conjunto da obra; se contribuem para o pensar historicamente, etc.

Diante do exposto, entendemos que os questionamentos e desafios da especificidade do digital na cultura escolar e na cultura histórica ainda permanecem em aberto. Este trabalho - ao mobilizar a discussão na área de história pelo viés do currículo, a partir do quadro teórico da abordagem social do discurso - pretendeu contribuir nesta reflexão, alertando para o fato de que esta temática está longe de ser esgotada. 


\section{Referências}

ALMEIDA, Anita Correia Lima de; GRINBERG, Keila. As WebQuests e o ensino de História. In: GONTIJO, Rebeca; MAGALHÃES, Marcelo de Souza, ROCHA, Helenice Aparecida Bastos. A escrita da história escolar: memória e historiografia. Rio de Janeiro: Editora FGV, 2009, p. 201-212.

ALMEIDA, Fábio Chang de. O historiador e as fontes digitais: uma visão acerca da internet como fonte primária para pesquisas históricas. Aedos, v. 3, n. 8,. p. 9-30, 2011.

ALMEIDA, Maria Elizabeth Bianconcini de. Integração de currículo e tecnologias: a emergência de web currículo. In: ENCONTRO NACIONAL DE DIDÁTICA E PRÁTICA DE ENSINO (ENDIPE), XV, 2010, Belo Horizonte. Anais ... Belo Horizonte: Universidade Federal de Minas Gerais, 2010.

ALMEIDA, Maria Elizabeth Bianconcini de. Maria Elizabeth de Almeida fala sobre tecnologia na sala de aula. Revista Nova Escola, São Paulo, jun./jul. 2010. Disponível em: <http://revistaescola.abril.com.br/planejamento-e-avaliacao/avaliacao/entrevistapesquisadora-puc-sp-tecnologia-sala-aula-568012.shtml?page=2>. Acesso em: 7 mar. 2014 .

ALMEIDA, Maria Elizabeth Bianconcini de; SILVA, Maria da Graça Moreira da. Currículo, tecnologia e cultura digital: espaços e tempos de web currículo. Revista e-curriculum, São Paulo, v. 7, n. 1, abr. p. 1-19, 2011. Disponível em:

<http://revistas.pucsp.br/index.php/curriculum/article/view/5676>. Acesso em: 7 mar. 2014.

ALMEIDA, Maria Elizabeth Bianconcini de ;VALENTE, José Armando. Web Currículo: integração de mídias nas escolas com base na investigação de fatos científicos para o fazer científico. In: SANTOS, Edméa Oliveira dos. Currículos: teorias e práticas. Rio de Janeiro: LTC, 2012. p. 121-136,

ARRUDA, Eucidio Pimenta. Museu virtual, prática docente e ensino de história: apropriações dos professores e potencialidades de elaboração de um museu virtual orientado ao visitante. In: ENCONTRO NACIONAL DOS PESQUISADORES DO ENSINO DE HISTÓRIA, 9, 2011, Florianópolis. Anais..., Florianópolis: Universidade Federal de Santa Catarina, 2011. p. 1-11.

BRASIL. Ministério da Educação. Secretaria de Educação Básica. Edital de convocação para o processo de inscrição e avaliação de obras didáticas para o Programa Nacional do Livro Didático PNLD 2015. Brasília, DF: Ministério da Educação, Secretaria de Educação Básica, 2013.

BRASIL. Ministério da Educação. Secretaria de Educação Básica. Guia de livros didáticos: PNLD 2012: História. Brasília, DF: Ministério da Educação, Secretaria de Educação Básica, 2011. 
BURITY, Joanildo A. Discurso, política e sujeito na teoria da hegemonia de Ernesto Laclau. In: MENDONÇA, D.; RODRIGUES, L. P. (Orgs.). Pós-estruturalismo e teoria do discurso: em torno de Ernesto Laclau. Porto Alegre: Edipucrs, 2008. p. 35-51.

COSTA, Marcella Albaine Farias da; RALEJO, Adriana Soares. Pensando a interface entre os livros didáticos de História e as demandas tecnológicas: negociações possíveis. In: SEMINÁRIO INTERNACIONAL AS REDES EDUCATIVAS E AS TECNOLOGIAS: TRANSFORMAÇÕES E SUBVERSÕES NA ATUALIDADE, VII, 2013, Rio de Janeiro. Anais... Rio de Janeiro: Universidade do Estado do Rio de Janeiro, 2013.

COSTA, Warley da; GABRIEL, Carmen Teresa. Currículo de história, políticas da diferença e hegemonia - diálogos possíveis. Educação \& Realidade, Porto Alegre, v. 36, n.1, jan./abr., p. 127-146, 2011.

CYSNEIROS, Paulo Gileno. Novas tecnologias na sala de aula: melhoria do ensino ou inovação conservadora? Informática Educativa, Los Andes, v. 12, n. 1, p. 11-24, 1999, Disponível em:< http://www.colombiaprende.edu.co/html/mediateca/1607/articles106213_archivo.pdf>. Acesso em: 7 mar. 2014.

FERREIRA, Carlos Augusto Lima; MARQUES, Edicarla dos Santos. Espaço e tempo como dimensões do conhecimento e objeto de ensino-aprendizagem em História. Revista História Hoje, v. 1, n. 2, p. 227-246, 2012.

FERREIRA, Márcia Serra; GABRIEL, Carmen Teresa. Disciplina escolar e conhecimento escolar: conceitos sob rasura no debate curricular contemporâneo. In: ALVES, Nilda; LIBÂNEO, José Carlos. Temas de pedagogia: diálogos entre didática e currículo. São Paulo: Cortez, 2012. p. 227-241.

FERREIRA, Márcia Serra; GABRIEL, Carmen Teresa; MONTEIRO, Ana Maria Ferreira da Costa. Sentidos de currículo e 'ensino de' biologia e história: deslocando fronteiras. trabalho encomendado GT Currículo. In: REUNIÃO ANUAL DA ANPED, XXX, LOCAL, 2012. Título da obra. Local: Editor, 2012.

FORQUIN, Jean-Claude. Saberes escolares, imperativos didáticos e dinâmicas sociais. Teoria \& Educação, n. 5, p. 28-49, 1992.

GABRIEL, Carmen Teresa. O “outro" como elemento incontornável na produção do conhecimento histórico. In: MONTEIRO, Ana Maria; PEREIRA, Amilcar Araujo. Ensino de história e culturas afro-brasileiras e indígenas. Rio de Janeiro: Pallas, 2013. p. 287-311.

GABRIEL, Carmen Teresa. Teoria da história, didática da história e narrativa: diálogos com Paul Ricoeur. Revista Brasileira de História. São Paulo, n. 64, v. 32, p. 187-210, 2012. 
GABRIEL, Carmen Teresa.; LEITE, Miriam Soares; VENERA, Raquel Alvarenga Sena. Abordagens discursivas de juventude no tempo presente: questões metodológicas nas análises de textos curriculares. 2012.. Projeto (Pesquisa) - MCTI/CNPq/MEC/CAPES, Universidade Federal do Rio de Janeiro, Universidade do Estado do Rio de Janeiro, Universidade da Região de Joinville, Rio de Janeiro, Joinville.

GABRIEL, Carmen Teresa; MORAES, Luciene Maciel Stumbo. História das disciplinas e "tempo histórico": quais narrativas em circulação no campo educacional? In: CARVALHO, Fábio Garcez de; FERREIRA, Márcia Serra; XAVIER, Libania. História do currículo e história da educação: interfaces e diálogos. Rio de Janeiro: Quartet: FAPERJ, 2013, p. 29-59.

HARTOG, François. Regimes de historicidade: presentismo e experiências do tempo. Belo Horizonte: Autêntica Editora, 2013.

LACLAU, Ernesto. Emancipação e diferença. Rio de Janeiro: EdUERJ, 2011.

LACLAU, Ernesto; MOUFFE, Chantal. Hegemonia y estratégia socialista; hacia uma radicalización de la democracia. Buenos Aires: Fondo de Cultura Económica, 2005.

LOPES, Alice Casimiro; MACEDO, Elizabeth. Teorias de currículo. São Paulo: Cortez, 2011.

LUCCHESI, Anita. A história sem fio: questões para o historiador da Era Google. In: ENCONTRO REGIONAL DE HISTÓRIA DA ANPUH-RJ, XV, 2012, Rio de Janeiro. Anais... Rio de Janeiro: Universidade do Estado do Rio de Janeiro, 2012. p. 1-09.

MACEDO, Elizabeth. Currículo como espaço-tempo de fronteira cultural. Revista Brasileira de Educação, v. 11, n. 32, p. 285-296, 2006.

MARCHART, Olivier. El pensamiento político posfundacional: la diferencia política em Nancy, Lefort, Badiou y Laclau. Buenos Aires: Fondo de Cultura Económica, 2009.

MENDONÇA, Daniel de. Como olhar "o político" a partir da teoria do discurso. Revista Brasileira de Ciência Política. Brasília, n. 1, jan./jun. p. 153-169, 2009.

MONTEIRO, Ana Maria Ferreira da Costa. Professores e livros didáticos: narrativas e leituras no ensino de História. In: MAGALHÃES, Marcelo de Souza; REZNIK, Luis; ROCHA, Helenice (Org.). A história na escola: autores, livros e leituras. Rio de Janeiro: Editora da FGV, 2009. p. 177-199.

PRENSKY, Marc. Nativos digitais, imigrantes digitais. Tradução de Roberta de Moraes Jesus de Souza, 2001. Disponível em: <http://pdfcast.org/pdf/nativos-digitais-imigrantesdigitais-marc-prensky>. Acesso em: 7 mar. 2014.

ROLLAND, Denis. Internet e história do tempo presente: estratégias de memória e mitologias políticas. :Revista Tempo. Rio de Janeiro, n. 16, p. 59-92, 2004. 
RÜSEN, Jorn. ¿Qué es la cultura histórica?: reflexiones sobre una nueva manera de abordar la história". [Unpublished Spanish version of the German original text in K.

Füssmann, H.T. Grütter and J. Rüsen, eds. (1994). Historische Faszination.

Geschichtskultur

heute. Keulen, Weimar and Wenen: Böhlau, 2009. p. 3-26.

SCHMIDT, Maria Auxiliadora. A formação do professor de história e o cotidiano da sala de aula. In: BITTENCOURT, Circe (Org.). O saber histórico na sala de aula. São Paulo: Contexto, 2009. p. 54-66.

SEDREZ, Lise Fernanda; CARVALHO, Bruno Leal Pastor de; GRINBERG, Keila. Debate online historia digital: ensino, pesquisa e divulgação. Disponível em:

<http://www.youtube.com/watch?v=T-aRq1c3QiY>. Acesso em: 5 mar. 2014.

Recebido em 31/03/2014

Aprovado em 13/08/2014

Universidade do Estado de Santa Catarina - UDESC

Programa de Pós-Graduação em História - PPGH

Revista Tempo e Argumento

Volume 06 - Número 12 - Ano 2014

tempoeargumento@gmail.com 